\title{
Ultrasonic Testing of Clinical Effect of Bicyclol on Liver Function Impairment Induced by Antithyroid Drugs
}

\author{
Y. MIAO* \\ Health Management Center, Beijing An Zhen Hospital Capital Medical University, Beijing 100029, China
}

Miao et al.: Ultrasonic testing of clinical effect of bicyclol on liver function impairment

\begin{abstract}
The objective of present study was to evaluate the effect of bicyclol on liver function impairment induced by antithyroid drugs. One hundred and eighty hyperthyroidism patients treated at the Beijing An Zhen Hospital for liver function impairment induced by antithyroid drugs from June 2015 to October 2018 were enrolled. The patients were divided into the research group receiving bicyclol and the control group receiving tiopronin. The therapeutic efficacy in the both groups was observed and the ultrasound results were recorded. The improvement in the levels of indicators such as aspartate aminotransferase, alanine aminotransferase and total bilirubin was significantly greater in the research group. The incidence of adverse reactions was also significantly lower in the research group. Moreover, the research group showed higher quality of life. In addition, ultrasound showed that treatment with bicyclol could arrest liver function impairment induced by antithyroid drugs. In conclusion, bicyclol could treat the liver function impairment induced by antithyroid drugs.
\end{abstract}

Key words: Ultrasound, bicyclol, antithyroid drugs, liver function impairment, therapeutic efficacy analysiss

Drug-induced liver inflammation (DILI) refers to liver damage caused due to hypersensitivity or reduction of tolerance to drugs during treatment. According to relevant data, DILI has risen to the fifth place in the global cause of death and has gained a high degree of attention ${ }^{[1,2]}$. In China, the rate of DILI is rather high, which ranks after viral hepatitis and fatty liver disease. Moreover, studies have shown that there were approximately $10-50 \%$ cases of increased alanine aminotransferase level in adults due to drugs ${ }^{[3,4]}$. Therefore, it is necessary to pay close attention to the prevention and control of DILI during clinical treatment.

There are many drugs which can cause liver damage, an image of the damage is shown in fig. 1, such as antitumor chemotherapy, antitubercular and antithyroid drugs. If the liver injury is relatively mild, then it can be improved after cessation of drug treatment. However, in severe cases or in those patients who require continuous drug therapy, liver-protective treatment should be given. Bicyclol tablets have been widely used to treat liver function impairment induced by antithyroid drugs. This study aims to analyze the effect of bicyclol on liver function impairment induced by antithyroid drugs.

One hundred eighty patients with liver function impairment induced by antithyroid drugs were enrolled.
All patients satisfied the clinical diagnostic criteria. These patients suffered from abnormal liver function, without any other complications or liver-protective therapy. There was no history of live diseases such as viral hepatitis, autoimmune liver disease, or abnormal liver function ${ }^{[5]}$. There were no HIV-infected patients, or those who had hormone and immunosuppressive agents in the past 6 mo. This study was approved by hospital ethics association. Patients and their families retained the right to know and signed an informed consent.

The patients in the research group were treated with bicyclol tablets, that is, the patients were instructed to take $25 \mathrm{mg}$ bicyclol tablets (Peking Union Medical

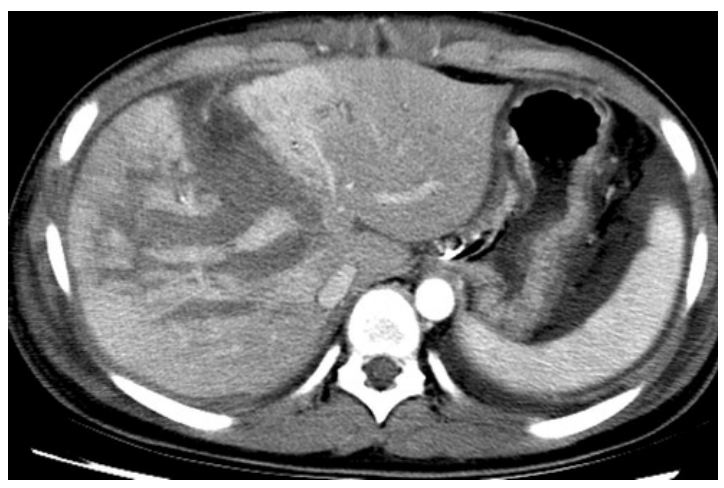

Fig. 1: Liver function damage induced by drugs 
and Pharmaceutical Co., Ltd., H20040467). The patients in the control group were instructed to take $0.1 \mathrm{~g}$ tiopronin tablets (Sinopharm Group Guorui Pharmaceutical Co., Ltd., National Pharmaceutical Standard H20073793). Both groups were treated for 3 mo. Meanwhile, ultrasound (German Sequoia 512 color Doppler ultrasound system, probe frequency of $3.5 \mathrm{MHz}$ ) was used to detect liver damage. The patient was placed at supine position and under eupnea. The portal vein detection point was selected at the portal vein junction 1-2 $\mathrm{cm}$ from the hepatic portal. The splenic vein detection point was selected at the hilum of spleen. Indices included inner diameter, mean blood flow velocity, blood flow of portal vein, and the inner diameter were measured ${ }^{[6-9]}$. The diagonal plane where the right hepatic vein connected to the inferior vena cava was recognized as standard, by which the normal value of live size was $\leq 14.0 \mathrm{~cm}$. Also, the normal inner diameter of the portal vein was $\leq 1.3 \mathrm{~cm}$.

Liver function indicators serum aspartate aminotransferase (AST), alanine aminotransferase (ALT) and total bilirubin (TBil) were compared. Meanwhile, adverse reactions including vomiting, fever, fatigue, poor appetite, dull pain in the liver area, diarrhea and rash if any were recorded. In addition, the quality of life was assessed using the Quality of Life Comprehensive Assessment Questionnaire (GOQL-74).

Statistical analysis was performed using SPSS21.0 software and measurement data was expressed as mean \pm standard deviation. Enumeration data were expressed by natural number (n)+percentage (\%).

As shown in Table 1, all liver function indicators were significantly improved in the research group $(\mathrm{p}<0.05)$.
Fig. 2 shows the ultrasound image of a patient after treatment. As shown in Table 2, the rate of adverse reactions was significantly lower in the research group $(\mathrm{p}<0.05)$. As shown in Table 3 , the quality of life scores were significantly higher in research group $(p<0.05)$. Hyperthyroidism is relatively common in clinical practice. According to relevant data, the rate of hyperthyroidism falls within 20-25\%. The causes of liver enzyme variation include relative hypoxia induced by high basal metabolic rate, elevated ALT levels resulted from liver cell necrosis, hyperbolism induced by massive secretion of thyroid hormone, liver cell degeneration induced by malnutrition, elevated gamma glutamyl transferase and alkaline phosphatase levels caused by intrahepatic cholestasis, increased bilirubin levels caused by direct interaction of thyroid hormone on the liver and poor binding of bilirubin and glucomannose. Liver dysfunction is caused by druginduced hepatitis, and some of which could also cause cholestatic hepatitis.

Bicyclol, a novel type synthetic antihepatitic drug can control the elevation of aminotransferase induced by chronic hepatitis. For other liver diseases such as cirrhosis, liver fibrosis, drug-induced hepatitis,

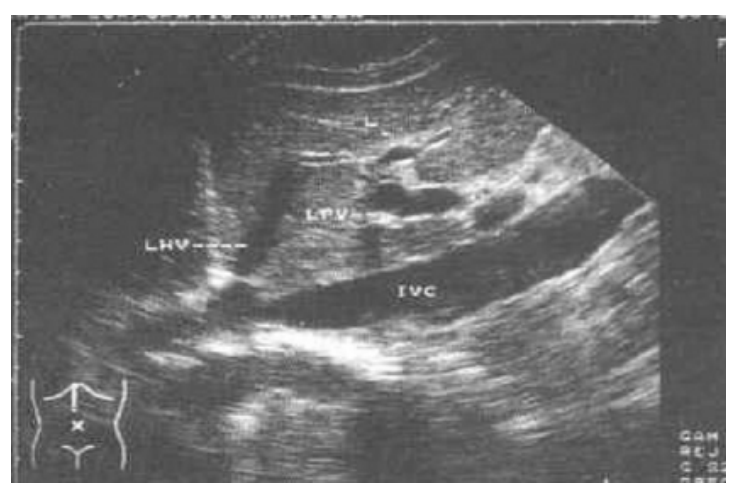

Fig. 2: The ultrasound image of a patient after treatment

TABLE 1: LIVER FUNCTION INDICATORS

\begin{tabular}{|c|c|c|c|c|c|c|c|}
\hline \multirow{2}{*}{ Group } & \multirow{2}{*}{ Cases } & \multicolumn{2}{|c|}{ ALT (U/l) } & \multicolumn{2}{|c|}{ AST (U/I) } & \multicolumn{2}{|c|}{ TBil $(\mu M)$} \\
\hline & & Before & After & Before & After & Before & After \\
\hline Research group & 90 & $42.30 \pm 12.50$ & $43.29 \pm 4.58$ & $38.37 \pm 6.73$ & $39.12 \pm 7.08$ & $17.22 \pm 2.14$ & $18.15 \pm 2.36$ \\
\hline Control group & 90 & $41.25 \pm 4.80$ & $68.36 \pm 8.86$ & $38.26 \pm 4.15$ & $66.90 \pm 8.85$ & $17.36 \pm 2.26$ & $33.27 \pm 4.59$ \\
\hline$t$ & & 0.25 & 9.04 & 0.83 & 11.36 & 0.36 & 8.31 \\
\hline$P$ & & $>0.05$ & $<0.05$ & $>0.05$ & $<0.05$ & $>0.05$ & $<0.05$ \\
\hline
\end{tabular}

Values are mean \pm standard deviation before and after receiving treatment

TABLE 2: INCIDENCE OF ADVERSE REACTIONS

\begin{tabular}{lccccc}
\hline Groups & Fever & Nausea and vomiting & Poor appetite & Fatigue & Incidence of adverse reactions (\%) \\
\hline Research group $(\mathrm{n}=90)$ & 2 & 2 & 2 & 0 & $6(6.67)$ \\
Control group $(\mathrm{n}=90)$ & 3 & 4 & 4 & 5 & $16(17.78)$ \\
$\mathrm{X}^{2}$ & & & & & 8.37 \\
$P$ & & & & $<0.05$ \\
\hline
\end{tabular}

Number of adverse reactions and \% of total in parenthesis 
TABLE 3: QUALITY OF LIFE

\begin{tabular}{lccccc}
\hline Groups & Mental function & Social function & Body function & Emotional life & Total score \\
\hline Research group $(\mathrm{n}=90)$ & $79.80 \pm 6.45$ & $80.19 \pm 9.04$ & $80.25 \pm 7.23$ & $78.05 \pm 8.38$ & $80.25 \pm 7.03$ \\
Control group $(\mathrm{n}=90)$ & $64.33 \pm 7.03$ & $70.26 \pm 8.26$ & $65.98 \pm 9.26$ & $62.46 \pm 9.50$ & $65.48 \pm 8.31$ \\
$t$ & 10.29 & 8.93 & 11.22 & 9.03 & 8.59 \\
$P$ & $<0.05$ & $<0.05$ & $<0.05$ & $<0.05$ & $<0.05$ \\
\hline
\end{tabular}

Values are mean \pm standard deviation

it is highly effective in lowering this enzyme level. Meanwhile, pharmacological studies have shown that bicyclol can reduce the elevated aminotransferase level in acute experimental liver injury or mouse immune hepatitis caused by $\mathrm{CCl}_{4}$ or D-galactosamine, or paracetamol. The improvement of AST, ALT and TBil was more significant in the research group $(p<0.05)$. The research group had less adverse reactions $(p<0.05)$. Bicyclol reduced the liver function impairment induced by antithyroid drugs, which is in line with studies reported ${ }^{[10-15]}$.

Bicyclol is an ideal drug to treat liver function impairment induced by antithyroid drugs, without causing any adverse reactions. Also, there is good patient compliance, and the curative effect is significant, which is worthy of popularization and application. There are many advantages with bicyclol administration such as protection of the liver cell membrane and mitochondria by eliminating free radicals and liver function preservation by protecting the liver cell nuclear DNA from damage as well as reducing apoptosis. Moreover, bicyclol could reduce chronic liver inflammation, protect liver cells from damage, promote collagen synthesis and reduce secretion, and effectively promote collagen degradation and absorption to inhibit the formation and development of fibrosis. However, there are also a few limitations in this study. For example, there is differences in the the course of treatment and effectiveness of drug treatment between this study and other studies, which could induce bias in the conclusions reached in this study. Also, the sample size is small. A larger study with greater sample size is needed in future to confirm the findings of this study.

\section{REFERENCES}

1. Wang AH, Zhang N, Feng X. Systematic evaluation of the efficacy and safety of bicyclol tablets in the treatment of druginduced liver injury. Chin Pharm 2015;26(09):1217-21.

2. Zhu HQ, Xiong WH. Therapeutic effect of bicyclol and polyallylphosphatidylcholine on hyperthyroidism. Chin Pharm 2015;18(08):1341-3.

3. Li TM, Chen Q, Tao L. Clinical study of bicyclol tablets in the treatment of liver function damage caused by anti-tuberculosis drugs. Chin J Clin Pharmacol 2018; 34(05):491-493+500.

4. Vincent L, Nicolas J, Philippe B, Catherine D, Isabelle RC, Frédéric $\mathrm{S}$, et al. Tolérance rénovasculaire du bévacizumabdans le cancer du sein. Valeurpronostique de l'hypertension et de la protéinurie. Bull Cancer 2015;102(11):1120-1126.

5. Makowsky M, Prebtani APH, Gelfer M, Manohar A, Jones C. Management of hypertension in people with diabetes mellitus: Translating the 2012 Canadian hypertension education program recommendations into practice. Can J Diabetes 2017;36(6):128-134.

6. Liu JB, Zhang JY, Chen XR. Meta-analysis of the efficacy of bicyclol in preventing drug-induced liver injury induced by anti-tuberculosis chemotherapy. J Zunyi Med College 2016;39(05):497-502.

7. Zhao JY, Li HQ. Clinical study on the treatment of druginduced hepatitis caused by drug-resistant tuberculosis by bicyclol tablets. Chin Pharm Ind 2016;25(04):46-48.

8. Yu D, Liu H, Bresser C. Peak load management based on hybrid power generation and demand response. Energy 2018;163:969-985.

9. Zvěřinová $\mathrm{M}$, Popelová $\mathrm{J}$, Pavel $\mathrm{P}$, Gebauer R, Jehlička $\mathrm{P}$, Rubáček M, et al. Is it possible to operate four heart valves in a patient with heart failure, congenital heart disease and pulmonary hypertension? Coret Vasa 2017;54(5):533-539.

10. Gunes HM, Babur Guler G, Guler E, Demir GG, Teber MK, Kizilirmak F, et al. Assessment of repolarization abnormalities in baseline electrocardiograms of patients with myocarditis. Turk J Med Sci 2017;47(5):1333-39.

11. Gao W, Baig AQ, Ali H, Sajjad W, Farahani MR. Margin based ontology sparse vector learning algorithm and applied in biology science. Saudi J Biol Sci 2017;24(1):132-8.

12. Sibbritt D, Davidson P, Giacomo MD, Newton P, Adams J. Use of complementary and alternative medicine in women with heart disease, hypertension and diabetes (from the Australian longitudinal study on women's health). Am J Cardiol 2015;115(12):345-350.

13. Weitsman T, Weisz G, Farkash R, Klutstein M, Butnaru A, Rosenmann D, et al. Pulmonary hypertension with left heart disease: Prevalence, temporal shifts in etiologies and outcome. The Am J Med 2017;10(08):513-518.

14. Naveed S, Dilshad H, Nafees M, Shinwari MI, Usmanghani K, Sarwar G. Pharmaceutical equivalent dissertation of metformin hydrochloride brands. Pak J Pharm Sci 2018;31(1):69-73.

15. Mehta BK, Banerjee S. Characterization of cognitive impairment in type 2 diabetic rats. Indian J Pharm Sci 2017;79(5):785-793.

This is an open access article distributed under the terms of the Creative Commons Attribution-NonCommercial-ShareAlike 3.0 License, which allows others to remix, tweak, and build upon the work non-commercially, as long as the author is credited and the new creations are licensed under the identical terms

This article was originally published in a special issue: Special issue on "Drug Development and Human Health in China"

Indian J Pharm Sci 2020:82(1)spl issue2;89-91 